\title{
The Professional Doctorate: Its Relativity to the PhD and Relevance for the Knowledge Economy
}

\author{
Dieter Fink \\ Edith Cowan University, Perth, Australia
}

\section{d.fink@ecu.edu.au}

\begin{abstract}
The Professional Doctorate (ProfDoc) is attracting increasing attention because of its perceived greater than the Doctor of Philosophy's (PhD's) focus on meeting the needs of the knowledge economy. The paper examines the nature of the ProfDoc vis-a-vis the $\mathrm{PhD}$ and identifies significant characteristics of the ProfDoc, especially in respect of relevance and performativity. It then analyses these characteristics in the context of the professional Doctorate in Business Administration (DBA) in Information Systems (IS) at an Australian university. An ethnographic approach is used to examine the internal (university) and external (student) environments of the DBA(IS). Recommendations are made to increase its effectiveness for the knowledge economy, including moving to a greater student and industry centred approach. Finally, conclusions are drawn to determine its relevance to the knowledge economy.
\end{abstract}

Keywords: Professional Doctorate, Doctorate of Business Administration, Information Systems, Doctoral Education, Knowledge Economy

\section{Introduction}

Recent debate about the value of the Doctor of Philosophy $(\mathrm{PhD})$ in Australia resulted in a review by the Australian Government Department of Education, Science and Training (DEST) of research training in doctoral programs. The outcome was a report authored by McWilliam et al. in 2002 titled "What can be learned from professional doctorates". The report concluded that "Doctoral education in Australia is currently under pressure to become more industry focused" and it was advocated that professional doctorates may be able to fulfil this role by developing and sustaining close collaboration between universities and industry.

The Professional Doctorate (ProfDoc) can be seen as an alternative to the PhD because it can provide an opportunity for the business professional to gain a doctoral qualification, albeit in a different mode. According to Lockhart and Stablein (2002), the approach meets the demands of professionals for ongoing learning, the desire to develop specific competencies for future employment and the opportunity to conduct doctoral research on a problem for the mutual benefit of

Material published as part of this journal, either on-line or in print, is copyrighted by the Informing Science Institute. Permission to make digital or paper copy of part or all of these works for personal or classroom use is granted without fee provided that the copies are not made or distributed for profit or commercial advantage AND that copies 1) bear this notice in full and 2) give the full citation on the first page. It is permissible to abstract these works so long as credit is given. To copy in all other cases or to republish or to post on a server or to redistribute to lists requires specific permission and payment of a fee. Contact Publisher@InformingScience.org to request redistribution permission. both the practioner and the academic.

Most importantly, however, professional doctorates have been viewed as becoming increasingly important to the emerging knowledge economy as they provide relevance (Tennant, 2004) and performativity (Usher, 2002) as will be discussed later.

The purpose of this paper is to seek answers to the following questions: 
- What are the theoretical dimensions that differentiate the ProfDoc from the PhD?

- How are the dimensions of the ProfDoc reflected in the context of a current professional doctorate program?

- What recommendations and conclusions can be drawn from the experiences gained in offering the ProfDoc?

The empirical aspects of the study were conducted by exploring the nature, tensions, relationships and developments of the Doctorate of Business Administration (Information Systems) program within the School of Management Information Systems (MIS) at an Australian university (University A). To achieve this aim, an ethnographic approach was taken that is qualitative and in context. As the approach implies, the researcher is an active participant in the program which enables him/her to have studied the program over a number of years. Ethnographic research is essentially phenomenological in nature and the researcher constructs a meaning in terms of the situation being studied. Hence, it falls within descriptive/interpretive research paradigm and 'lawlike' generalisations can not be derived (Remenyi, Williams, Money, \& Swartz, 1998). Nevertheless, the conclusions drawn and recommendations made in this paper should be of interest and value to other universities offering or contemplating to offer a ProfDoc.

\section{The Professional Doctorate}

The role of the ProfDoc vis-à-vis the PhD reflects the ongoing debate on how to manage the tension between relevance and rigour in research (Lytras, 2005). As indicated above, the issue of relevance has emerged strongly in the knowledge economy. Tennant (2004) provides a strong analysis of the issue and concluded as follows. "Relevance no longer equates with the 'application' of knowledge 'to' the workplace, rather, the workplace itself is seen as site of learning, knowledge and knowledge production, hence the term 'knowledge worker"' (p. 433). The professional doctorate makes this possible by linking the student's education with workplace issues.

Others have taken the need for the industry focus further by perceiving the professional doctorate as a hybrid curriculum represented by "the intersection between the university, the candidate's profession and the particular work site of the research" (Malfroy \& Yates, 2003, p. 120). This is reflected in Figure 1.

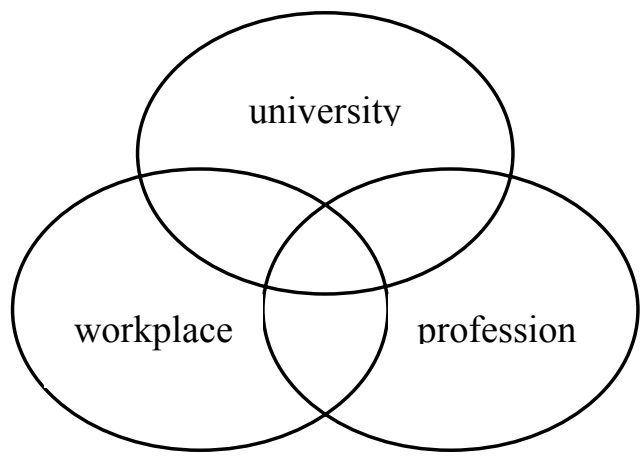

Figure 1: The Hybrid Curriculum of the Professional Doctorate (Adapted from Lee, Green and Brennan (2000) referenced in Malfroy and Yates (2003))

Usher (2002) also recognises the importance of ProfDocs in relation to the knowledge economy but in relation to performativity. Quoting Lyotard (1984), Usher argues that "knowledge is now legitimated by its performativity or capacity to enhance the efficiency and effectiveness of the 
socio-economic system" (p. 146). By this he means that they have a strong role to play in improving the workplace and/or professional practice in innovative and flexible ways. Hence doctoral education should be dynamic and industry-driven rather than the traditional and university-driven PhD. He argues, quoting Gibbons et al (1994, p. 81), that "knowledge can no longer be regarded as discrete, its production defined by clear rules and governed by settled routines" (p. 146). By this he refers to the traditional university education model.

The distinction between the ProfDoc and the $\mathrm{PhD}$ in relation to the knowledge economy can also be observed by examining the modes of knowledge that each provides. This has its origins in the work done by Gibbons et al (1994) who identified Mode1 and Mode 2 of knowledge creation. When related to doctoral education, it becomes apparent that Mode 2 represents the professional doctorate's prime objective. Usher (2002, p. 146) quotes Gibbons et al (1994) when describing Mode 2 knowledge as follows:

"The new mode [Mode 2] operates within the context of application in that problems are not set within a disciplinary framework. It is trans-disciplinary rather than mono- or multidisciplinary. It is carried out in non-hierarchical, heterogeneously organised forms which are essentially transient. It is not being institutionalised primarily within university structures." (p. vii)

Mode 1 by contrast is knowledge produced in universities and, quoting Gibbons et al (1994), is about "traditional 'truths' accumulated over time ... universal, objective, disciplined, planned, tested and reliable findings" (Usher, 2002, p. 8) Usher concludes that "conventional PhD by thesis is too embedded in Mode 1" (p. 150) but since "Mode 2 knowledge is produced in the context of application it is inevitably performative. It is perhaps for this reason that Mode 2 is seen as a more appropriate conception of knowledge for the knowledge economy." (p. 147)

The above and other differences between the ProfDoc and the $\mathrm{PhD}$ are shown in Table 1 and briefly summarised as follows. The former is outcome driven (e.g. workplace improvements) and student driven (e.g. practioner researching his/her workplace) while the latter is subject to the governance of the university and therefore is largely process driven. By having a reductionist focus rather than a broad focus, the $\mathrm{PhD}$ is generally regarded academic and oriented to a particular discipline. Perry and Cavaya (2004, p. 411) provide a succinct distinction in this respect- "the $\mathrm{DBA}$ is a professional doctorate for managers and the $\mathrm{PhD}$ is a professional doctorate for academics."

For content, the traditional academic environment pursues Mode 1 knowledge, i.e. for its own sake, rather than being pursued because of need for the knowledge economy, i.e. relevancy and performativity. The context in which this done differs. PhDs are undertaken in the context of discovering new knowledge and innovative theoretical perspectives in their discipline (Sarros, Willis, \& Palmer, 2005). By contrast ProfDocs are completed where the context is the application itself leading to improvements in the workplace- "the workplace becomes the site of research" (Usher, 2002, p. 150).

As outcomes, $\mathrm{PhDs}$ produce theses and papers that are disseminated widely while a ProfDoc produces an artefact in the form of a project report or thesis that aims to provide a solution to a particular problem. Thus knowledge gained from a completed $\mathrm{PhD}$ has wide applicability while the opposite holds for the ProfDoc. Entry to a PhD is through research (e.g. by completing an honours degree) and processes are linked to and driven by the university. The candidate works closely with his/her supervisor. The ProfDoc, on the other hand, meets the expectation of possessing a higher degree (such as an MBA), not necessarily research-based, and importantly possessing professional experience. The candidate maintains links with the university as well as industry and works collaboratively with a group from industry. 
Table 1: Comparison between PhD and the Professional Doctorate

\begin{tabular}{|l|l|l|}
\hline & PhD & ProfDoc \\
\hline Orientation & Process driven & Outcome driven \\
& University driven (clunky) & Student driven (flexible) \\
& $\begin{array}{l}\text { Fresh researcher (seeking academic } \\
\text { training) }\end{array}$ & $\begin{array}{l}\text { Experienced practioner (seeking } \\
\text { qualifications) }\end{array}$ \\
& $\begin{array}{l}\text { Reductionist focus ("much study } \\
\text { about little") }\end{array}$ & $\begin{array}{l}\text { Broad focus ("much study about } \\
\text { much") }\end{array}$ \\
\hline Content & $\begin{array}{l}\text { Mode 1 knowledge } \\
\text { Context of discovery } \\
\text { Discipline }\end{array}$ & $\begin{array}{l}\text { Mode 2 knowledge } \\
\text { Context of application } \\
\text { Workplace }\end{array}$ \\
\hline Outcomes & Thesis & Project \\
& Seeks newness (new knowledge) & Seeks improvements (advanced \\
& Wractice) \\
& Nide dissemination & Narrow dissemination \\
\hline Process & Entry through research & Entry through experience \\
& Links with university & Links with industry \\
& Research training & Action research \\
& Collaborative \\
\hline
\end{tabular}

The above indicates that the ProfDoc should not be a watered down version of the $\mathrm{PhD}$ but offer a valid alternative in doctoral education. McWilliam et al (2002) refer to this being "differently rigorous". There do, however, exist common elements for the two programs. Both ProfDocs and $\mathrm{PhDs}$ have an agenda of developing new knowledge that contributes to the development of professions and communities in some form or another (Malfroy \& Yates, 2003). Furthermore, to be able to create Mode 2 knowledge requires Mode 1 knowledge albeit not in its pure form. As suggested by Usher (2002) - "Mode 2 knowledge producers still need to be initially trained as Mode 1 researchers- hence perhaps the still significant role that universities have in research training and building research capacity.“ (p. 149)

The case can be made that the distinction between the ProfDoc and $\mathrm{PhD}$ may disappear. Tennant (2004) argues that academics are part of the knowledge economy and therefore need to be creative, innovative, enterprising thereby assuming the characteristics of a knowledge worker. "If this argument is accepted than the scholarly workplace is not different from other workplaces and the rational for the Ph.D./Prof.Doc. distinction collapses" (Tennant, 2004, p. 435). Usher (2002) goes so far as to claim that universities have "lost their traditional status as primary producers of 'worthwhile' knowledge" (p. 148) and have become part of a globalised knowledge market in which they have to compete with an IT enabled information and knowledge explosion. Thus the $\mathrm{PhD}$ would no longer occupy a privileged position.

\section{The DBA(IS) Program}

ProfDocs have existed in non-business disciplines, particularly in education, for many years (Sarros, Willis, \& Palmer, 2005). For the business discipline, the DBA is obviously of relevance to the professional and a wide choice exists within the Australian university system. According to Sarros et al. (2005), twenty Australian universities offer a DBA degree with the first starting in 1993 at the Victoria University of Technology. At University A the Doctorate of Business Administration commenced in 2001 within a particular academic unit, namely the School of Management Information Systems (MIS). The product brochure of the School of MIS at University A provides the following information about the program. 
"The DBA(IS) is a professional doctorate in business administration with a particular focus on Information Systems. The program involves both coursework and research and is designed for senior managers who need to develop an in-depth understanding of the latest thinking and technologies that are shaping the global world of electronic business. The DBA degree provides an opportunity for participants to develop a specific expertise in a chosen area."

The DBA(IS) brochure goes on to state that the program has been designed to fit in with the demands of busy senior managers. Teaching takes place during weekend sessions, and involves a mixture of seminars, invited lectures, group discussions, case studies and technology reviews. The course work stage is the first stage of study and comprises three unique units (Strategies for the Virtual Organisation, Managing Organisational Knowledge, The Information Economy) covering advanced topics on the impact of ICT in today's organisation. For each unit, students produce a 'publishable' paper. In addition, a fourth unit on Research Management (Research Management for IS) covers the latest methodologies and tools of the researcher, and lays the basis for the second stage of study. The second stage of the DBA is individual research towards a thesis in the area of IS.

The research stage consists of a thesis completed over 18 months of full time study or equivalent. This is a major thesis and together with the "Research Management in Information Systems" unit results in research being $70 \%$ of the program. By contrast some DBAs offer an alternative model which "treats the DBA as an advanced MBA with a company-based project component" (Lockhart \& Stablein, 2002, p. 196). University A's DBA(IS) thesis expectations conform to the view of Sarros et al (2005) of a substantial thesis, namely that it is "focused on researching real business and managerial issues through a critical review and systematic application of appropriate theories and research" (p. 43).

The program offers an exit award titled "Master of Information Systems Leadership" after the completion of the four coursework units and further units of the current Master of Management Information Systems (MMIS). Candidates who complete these unit qualify for this award and are regarded as potential leaders in the IS discipline. Hence, the naming of the award.

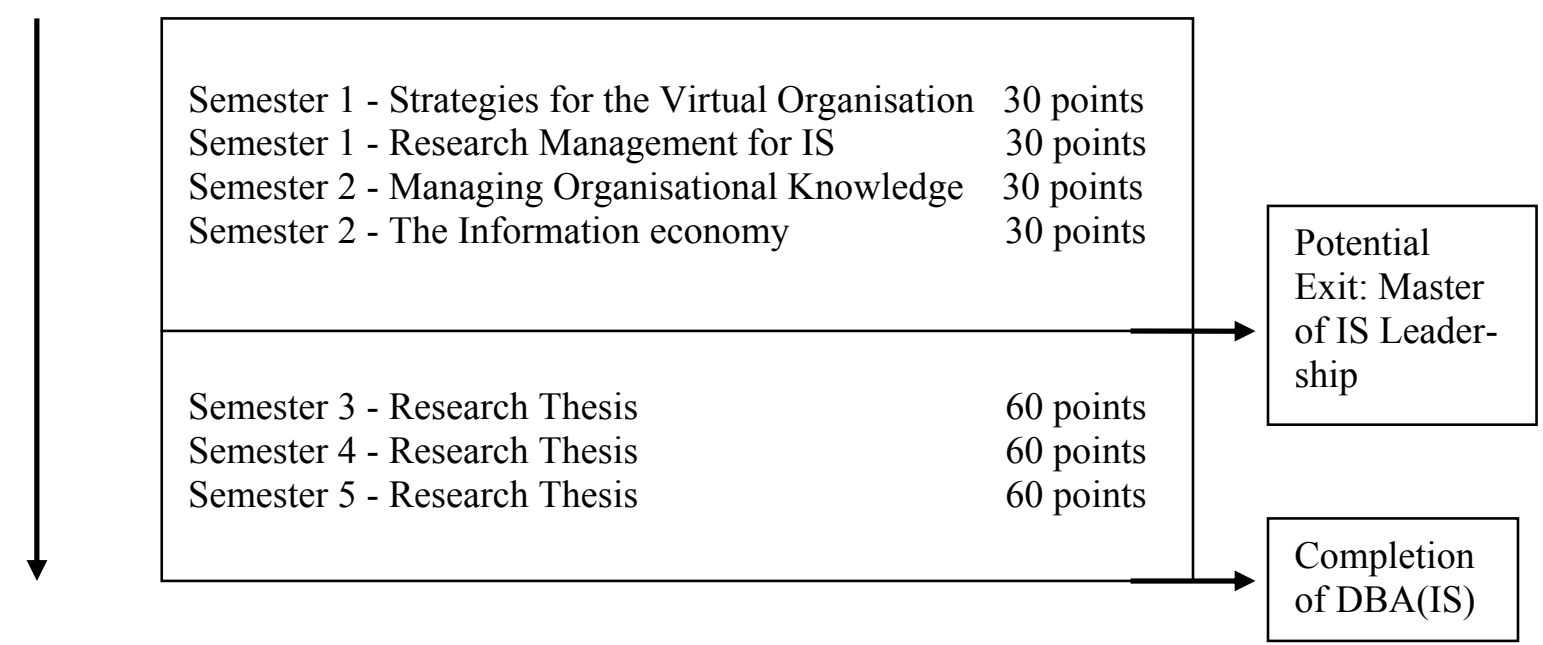

Figure 2: Schematic Diagram of the Structure of UNIVERSITY A's DBA(IS) 
By contrast, the PhD program at University A is entirely based on the completion of a research thesis. This typically takes between three and four years to complete and the candidate works exclusively under the supervision of a Principal Supervisor with some support from an Associate Supervisor. The PhD has been in existence for a much longer period than the DBA(IS) and hence university processes are mature and well defined.

\section{The DBA(IS) in Context}

As stated earlier, a key objective of the paper is to explore the DBA(IS) program in context from which conclusions and recommendations can be derived. This is provided in the following sections and is reflected in Figure 3.

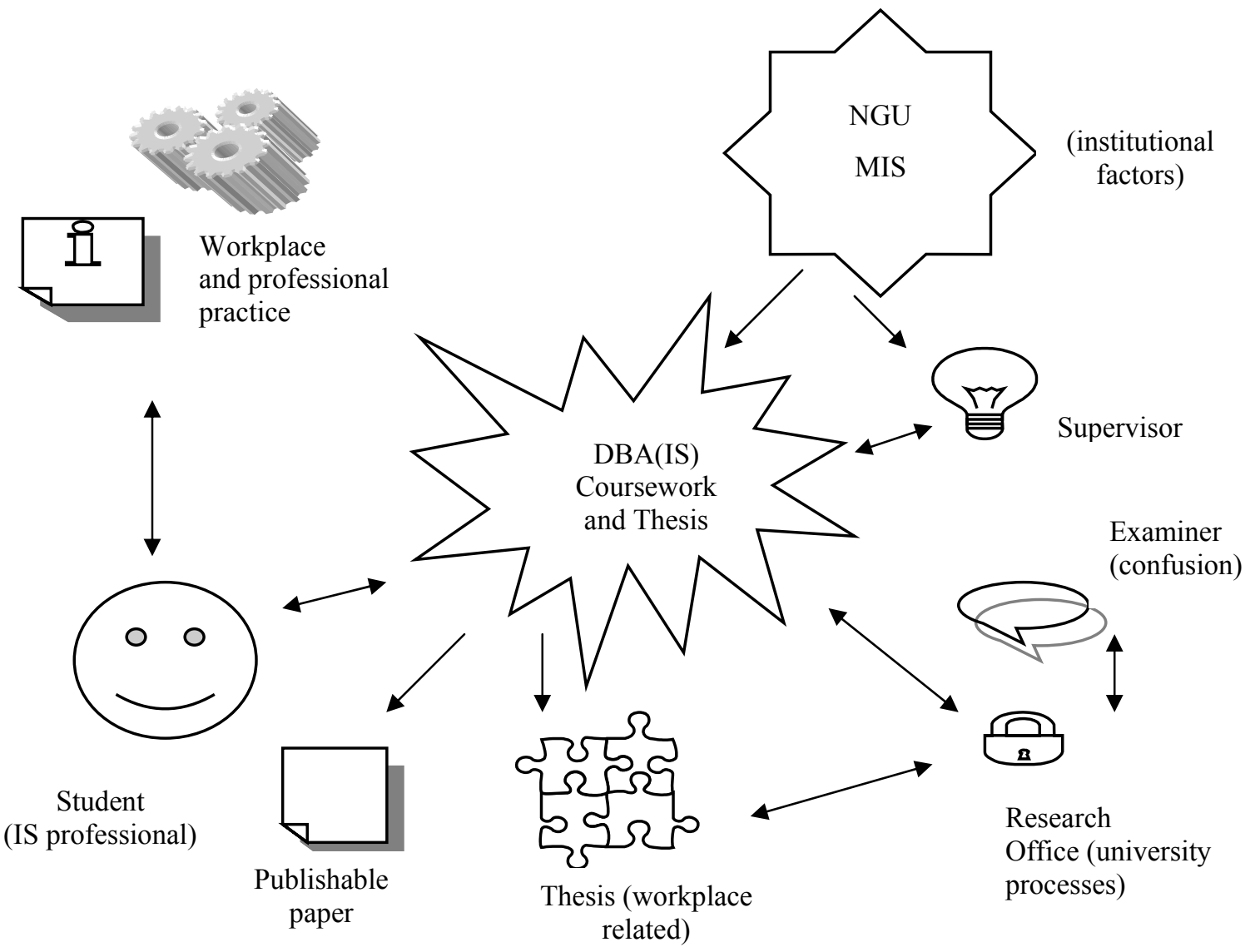

Figure 3: The DBA(IS) in Context

\section{The Internal Context}

The example of the DBA(IS) at University A illustrates how institutionalised developments have shaped institutional characteristics. University A is one of Australia's New Generation Universities (NGUs) who had its origins in a College of Advanced Education that was formed by the merger of a number of localised Teacher Training Colleges. The Faculty of Business was a new development and broadened the scope of activities of the college. In 1988 the Australian government disbanded the two tier system by giving colleges university status and the NGUs were founded. Up to that point, the institution was primarily a teaching one focusing on vocational training with strong links to the workplace. For example, the School of MIS taught IBM main- 
frame subjects and its graduates found ready employment because of vocational skills that were in high demand.

With the formation of University A, a new set of vision and missions were developed deemed to reflect the nature of a NGU. The strategic direction of University A is clearly evident in its website and policy documents and convey a spirit of enterprise and professionalism in educating the knowledge-based service profession which includes business disciplines. In parallel, the School of MIS formed its research centre with the theme of conducting research on e-business in the networked global economy. The design of its DBA(IS) program reflects this emphasis on ebusiness in the units taught as outlined in the earlier discussions.

While implementing the course work component of the DBA(IS) was achieved smoothly, some tension exist for the research component. The DBA(IS) is managed by the same processes as the $\mathrm{PhD}$ and therefore the two programs are judged as being similar rather than distinctive. This has created potential tensions in a number of areas. First, there is the question of what should be the framework of a doctoral thesis. DBA(IS) students, by doing research with the aim of improving their workplace or their professional practice, provide more contextualised research and therefore place greater emphasis on data rather than $\mathrm{PhD}$ students who are allowed more time for developing research frameworks for the collection of data (see Malfroy \& Yates, 2003).

Second, thesis work is managed through the system of university supervisors, the current "primary pedagogical technology" (Tennant, 2004, p. 434), rather than by outsiders from the workplace which would be more appropriate for the ProfDoc. The problem here is that academics are put into a position they would not be used to when supervising a $\mathrm{PhD}$ in their area of expertise, namely to learn from students who are senior professionals and who are potentially more knowledgeable than they are in respect of the research topic.

Third, theses are examined by academics with appropriate qualifications and reputations in the topic rather than by practioners from the field. Furthermore, instructions to examiners for both the DBA(IS) and PhD are the same except for the proviso that the DBA(IS) thesis was preceded by course work. This lack of distinction between the two programs is not an unusual occurrence as noted by Perry and Chavaya (2004) - "DBA dissertations and the $\mathrm{PhD}$ thesis is examined in the same way using the same examination criteria and the same notes for examiners" (p. 416). Perry and Chavaya (2004), quoting Phillips (1992), found a high degree of confusion among examiners of DBA and $\mathrm{PhD}$ theses in New Zealand and Australia as to their examination responsibilities.

\section{The External Context}

The contemporary advertisement used by the DBA(IS) program has the following heading:

"Want to take your business career to a higher level?". It outlines the focus of the program and its suitability for applicants looking for flexible delivery options to suit their busy schedule. The aim of the advertisement therefore is to attract qualified and experienced professionals who want to gain a doctoral qualification and do so in a way that meets their socio-economic situation. In accordance with the ethnographic approach of the research, two current and two past students were asked to provide key statements of what the DBA(IS) meant to them. They were selected at random from a cohort of about thirty students.

Student A, General Manager and Construction Manager of a large building company and about to submit his thesis stated: "One aspect of the course that stands out for me is the new knowledge gained from my study and the ability to put this new knowledge to use, whether it is through having a better understanding of why things happen or having the skills to put together a complex business plan and being able to implement it throughout the organisation." This reflects very well the key objectives of the ProfDoc, namely that knowledge is acquired in the context of the application, the content is the workplace and improvements are sought to advance practice. 
Student B, Manager within the Australian Police Force, offered to following comment- "I feel that I fit neatly into the classification of DBA students as being mature candidate with considerable levels of work experience, and usually part time students fitting in their study alongside their work and other domestic commitment." The comment reflects another side of the ProfDoc, namely its attractiveness to an experienced practioner who is seeking to advance his qualifications. Entry to the program is through demonstrating previous experience. It is also student driven providing flexibility to the student to fit study activities into a busy schedule.

Graduate A, Manager in a large State Government Department, offered this observation: "The DBA has enhanced my status and position as mentor within the Corporate Governance Directorate and has opened doors and provided promotional opportunities to the extent that I am invited as a specialist onto management review and advisory panels." The key characteristics of the ProfDoc reflected in the comment are its outcome driven orientation and seeking to gain advanced practice that enables the graduate to play a key role on advisory panels.

Graduate B, Manager of an Institute of Social and Economic Policy in Thailand, stated: "I think the DBA course gave a lot of new dimensions to my job. It helped develop my understanding of technologies in information systems and also broaden my management skills and knowledge of business issues in electronic business." These comments illustrate the broad focus of the program ("much study about much") in contrast to the narrow focus of a $\mathrm{PhD}$. This outcome seems to have met the expectations of the graduate very well.

\section{Recommendations}

There are a number of areas that require attention in order to improve the effectiveness of University A's DBA(IS) and thereby increase its relevance for the knowledge economy. First, the university, as well as the body of potential examiners, need to be educated and made aware that a DBA thesis is not the same as a $\mathrm{PhD}$ thesis. As indicated earlier, some confusion exists currently. For instance, when Perry and Chavaya (2004) surveyed doctoral examiners and requested them to define what they understood the 'contribution' a thesis should make they found responses to be "fuzzy and diverse" (p. 415) and included term such as 'leading to publication', 'adds to what we know', 'provides insight', 'integrates different things we know', 'conceptualises something new'. Perry and Chavaya warn against the tendency of professional doctorates becoming too academic in nature and suggest DBA examination criteria as follows:

- Research domain;

- Literature review;

- Methodology of data collection and analysis;

- Conclusions and implications; and

- Presentation.

Second, an important feature of ProfDocs is the development of a strong cohort or community of professional practice. This distinguishes the program from the $\mathrm{PhD}$ as students come from industry or professional practice and are used to a team approach. Furthermore, they study broader topics and rely much on networking and collaboration to conduct their study. The need for a community is further increased when ProfDocs are offered online. The current DBA (IS) is in need of a stronger community for both local and offshore students. The first step has been undertaken by providing an online community group.

Third, the most successful professional doctorates are the EdD and DPsych for the key reason that they cater for the needs of particular professional groups, namely education and psychology respectively (Sarros et al, 2005). These programs are termed 'deep-linked' in that the community of 
learning comprises the relevant industry/profession and the student. With some exceptions, students in the current DBA (IS) are relatively 'surface linked' to industry. Consideration should be given to approaching the relevant profession for the DBA (IS) program, namely the Australian Computer Society (ACS) to provide the desired deep linkage.

Finally, the program should recognise the increasing trend towards flexibility in unit offerings and research. The program should make use of a scaffolding framework providing the student with a pathway that is suitable to him/her and agreed upon by negotiation. This approach was promoted by Professor John Stephenson from Middlesex University at the 2004 Conference on Professional Doctorates at Deakin University. He advocated a shift in the primary focus of programs from the university to the professional environment and student with varying degrees of support and input from the university. The control of content, research, method, context, assessment and nature of the partnership between university and profession should be determined by the learner within a generic framework of procedures and support offered by the university. Through this, "The role of the university is transformed into one of providing an enabling framework and a credentialing mechanism.” (Tennant, 2004, p. 437)

\section{Conclusions}

University A's DBA(IS) degree is now in its fifth year and from the contextual analysis carried out and reported above, a number of conclusions can be drawn as to its relevance for the knowledge economy and its relativity to the $\mathrm{PhD}$ program.

Feedback indicated that the nature of the DBA(IS) program meets the need of students very well and reflects strongly the objectives of the ProfDoc. In this way, the program is clearly suitable to meet the expectations of the knowledge economy. However, while the course work stage is operating smoothly, there are tensions within the university in respect of the research stage. Essentially they come about because of the lack of understanding on the differences between the ProfDoc and the $\mathrm{PhD}$. In other words, they require different procedures to meet their respective objectives. Differences were identified as determining the unique (for the DBA) and different (to the $\mathrm{PhD}$ ) thesis content, supervision arrangements and thesis examination criteria.

It is difficult to independently assess the value of the DBA(IS) in respect of delivering new knowledge, albeit for the work place and/or the profession, via theses examiners' reports. The DBA(IS) thesis is currently still being assessed along the lines of a $\mathrm{PhD}$, for examples through applying thesis examination criteria that are 'academic' rather than 'applied'. The DBA(IS) has not reached a 'mature' stage because is has not yet been recognised by the university as being on par with the $\mathrm{PhD}$; it is still governed by thesis procedures applicable to the latter.

There are a number of reasons why the above situation may change so that the ProfDoc emerges as the desirable doctoral qualification. First, students undertaking ProfDocs are experienced and mature practioners who bring with them extensive prior knowledge of potential interest to the university (for e.g. in obtaining industry-based research funding). Second, the number of students seeking advanced qualifications relevant to their business careers (DBA) is higher than those seeking training for an academic career $(\mathrm{PhD})$.

This paper provides a theoretical comparison of the ProfDoc and the $\mathrm{PhD}$ and insights into the operations of a current ProfDoc. The conclusions drawn cannot be generalised across all ProfDocs as the analysis was restricted to a particular program, namely the DBA(IS) at University A. Furthermore, the sample of students interviewed is small and the interview itself was restricted to obtaining a broad view about the program. To explore the topic further and to identify generalisable trends, it is suggested that cross-institutional research be carried out that establishes the current as well as the future status of ProfDocs vis-a-vis PhDs. The former's potential significance for the modern economy makes this a worthwhile endeavour. 


\section{References}

Gibbons, M., Limoges, C., Nowotney, H., Schwarzman, S., Scott, P. \&. Trow, M. (1994). The new production of knowledge; The dynamics of science and research in contemporary societies. London: Sage.

Lee, A., Green, B. \& Brennan, M. (2000). Organisational knowledge, professional practice and the professional doctorate at work. In J. Garrick \& C. Rhodes (Eds.), Research knowledge at Qork. London: Routledge.

Lockhart, J.C., \& Stablein, R.E. (2002). Spanning the academy - practice divide with doctoral education in business. Higher Education Research \& Development, 21(2), 191-202.

Lyotard, J.F. (1984). The postmodern condition: A report on knowledge. Manchester: Manchester University Press.

Lytras, D. (2005). An interview with Tom Davenport. Quarterly Bulletin of AIS Special Interest Group on Semantic Web and Information Systems, 2 (2). Retrieved 1 May 2005 from www.sigsemis.org

Malfroy, J., \& Yates, L. (2003). Knowledge in action: Doctoral programmes forging new identities. Journal of Higher Education Policy and Management, 25(2), 119-129.

McWilliam, E., Taylor, P., Green, B., Holland, S., Maxwell, T., \& Thompson, P. (2002). What can be learned from professional doctorates. Retrieved 11 March 2005 from www.dest.gov.au

Perry, C., \& Cavaya, A. (2004). Australian universities' examination criteria for DBA dissertations. International Journal of Organisational Behaviour, 7(5), 411-421.

Phillips, E. (1992). The $\mathrm{PhD}$ - assessing quality at different stages of development. In O. Zuber-Skerritt (Ed.), Starting research - supervision and training. Tertiary Education Institute, University of Queensland, Brisbane.

Remenyi, D., Williams, B., Money, A., \& Swartz, E. (1998). Doing Business Research in Business and Management. London: Sage Publications.

Sarros, J.C., Willis, R.J., \& Palmer, G. (2005). The nature and purpose of the DBA - a case for clarity and quality control. Education \& Training, 47(1), 40-52.

Tennant, M. (2004). Doctoring the knowledge worker. Studies in Continuing Education, 26(3), 431-441.

Usher, R. (2002). A diversity of doctorates: fitness for the knowledge economy. Higher Education Research \& Development, 21(2), 143-153.

\section{Biography}

Dr Dieter Fink is an Associate Professor and co-ordinator for the DBA in Information Systems in the School of Management Information Systems at Edith Cowan University in Perth, Western Australia. Prior to joining academe he worked as a Systems Engineer for IBM and as Manager, IS Consulting for Arthur Young (now Ernst \& Young). He has been a visiting academic at a number of universities: Australian National University, University of Cape Town, Canterbury University, and Free University of Berlin. His primary interest is in IT Governance which includes establishing and measuring the value of IT investments, IT adoption, and minimising the risk of ecommerce and e-business. Further details about him are provided at http://myprofile.cos.com/fink22 